- It has been well established that the work patterns of male and female dentists differ.

- 95\% of respondents felt that a postgraduate qualification would assist their career prospects.

- Over 91\% considered childcare should be shared equally between both parents.

- 34\% of males and 56\% of females stated they would take time out of their careers when their children were of pre-school age.

- 3\% of those intending to enter general dental practice would work exclusively in the NHS.

\title{
A survey of dental school applicants' career intentions and the balance with family life
}

\author{
F. M. J. Stewart, ${ }_{1}^{1}$ J. R. Drummond, ${ }^{2}$ L. Carson ${ }^{3}$ and G. Hoad Reddick ${ }^{4}$
}

Purpose To investigate the career plans of prospective dental students and how they foresee their work life balance.

Method Applicants to Dundee and Manchester dental schools

completed anonymous questionnaires when they attended for interview. Results The useable response rate was $94 \%(n=436)$. The majority of the respondents (91.3\%) intended working full time when they enter the workforce, with no significant variation detected between males and females. The cohort anticipated their mean salary to be just over $£ 28,000$ five years into their career, although the males felt they would be earning $£ 5,000$ more than the females. Individuals of Pakistani and Indian origin thought they would earn most, and Asians least.

Sixty-five per cent would enter general dental practice and, of these, only $2.8 \%$ expected to work exclusively within the NHS. Fifteen per cent intended to go into the hospital dental service, with orthodontics the most popular choice of subspecialty (43.7\%), followed by oral surgery (31.1\%). Significant variation was seen between ethnic groups, with the hospital and community dental services being more popular with those who identified themselves as of non-white ethnic origin, although the majority would still plan on entering general dental practice.

Almost half (44.5\%) would take time out of their career to concentrate on childcare when children were of pre-school age, with a further $11 \%$ taking longer. Ninety per cent of females and $70 \%$ of males anticipated taking time out, of a varying duration. Half of the respondents indicated that they felt a child would affect their career to a moderate extent. Conclusions The dental profession will be severely affected if both males and females take time out of their careers in the future. As well as a work force shortage, the problems of accessibility to NHS dental services will be exacerbated if fewer dentists choose to provide NHS care.

Workforce planning is an area often criticised in the dental profession. Figures for Scotland reveal that the number of general dental practitioners registered with NHS Scotland has risen steadily over the past ten years, by an average of just over

\footnotetext{
${ }^{1 *}$ Lecturer in Restorative Dentistry, ${ }^{2}$ Senior Lecturer/Honorary Consultant in Restorative Dentistry, Dundee Dental School, Dundee University, ${ }^{3}$ Lecturer in Psychology, Division of Psychology, School of Social and Health Sciences, University of Abertay, Dundee, ${ }^{4}$ Senior Lecturer, Turner Dental School, University of Manchester

*Correspondence to Fiona Stewart, Dundee Dental School, Dundee University, Dundee. DD1 4HN
}

Email: f.m.j.stewart@dundee.ac.uk

\section{Refereed paper}

Received 22.10.03; Accepted 19.04.04

doi: 10.1038/sj.bdj.4812391

(๑) British Dental Journal 2005; 198: 713-717
$2 \%$ per annum. Projections indicate that this rise will continue at a slightly slower rate until around 2006, after which it will tail off until the number of general dental practitioners leaving will be greater than those joining the profession. ${ }^{1}$

On initial inspection the increase in number of dentists UK wide is promising, but further examination of the figures reveals a potential crisis in the future. Currently $32 \%$ of the available dental workforce in the UK is female. New UK graduates are now equally split between the sexes, although the proportion of females is increasing above that of males in Scotland, where 65\% of newly qualified dentists will be female by 2006. Projections suggest that the dental workforce will be equally split between the genders by 2030.

These changes in the demographics of the profession will have far reaching effects if the discrepancies between male and female work patterns continue as shown in research to date. ${ }^{2-6}$ These findings include:

- Women are more likely to take career breaks more often and for longer than their male colleagues.

- Women's main reason for career breaks is child rearing, whereas men's are mostly due to ill health.

- Following a break, dental professionals are more likely to return to working fewer hours than previously.

- Women are less likely to become general dental practice owners, or occupy promoted grades in both the hospital and community dental services.

The authorities are aware of the potential problems and efforts are being made to try to minimise these. A report entitled 'Better Opportunities for Women Dentists', published in 2001, recommended women return to a career in dentistry following a career break. $^{7}$ This led the Government to invest in the Keeping in Touch Scheme, established in England, for both men and women out of practice.

A further problem was highlighted by a recent survey of Scottish General Dental Practitioners, which showed two thirds planned to retire early, with half of those reducing their working hours before retirement. This reduction in working hours is almost certain to impact on the availability of NHS dental services. ${ }^{8}$

\section{STUDY DESIGN AND OBJECTIVES}

Contrary to most studies and projections, which are based on historical data concerning work patterns, ${ }^{9-11}$ this study was designed to investigate the plans of those who were short-listed for entry to dental school. The purpose of this study was to see 
whether trends exist between students of similar backgrounds, ethnic groups or gender. Four hundred and sixty-four anonymous questionnaires were distributed to applicants to the dental undergraduate courses at Dundee and Manchester when they attended for interview in the spring of 1998 and 1999. The participants were advised that their subsequent interview would not be affected, since the interviewers would not see their completed responses, nor ask any questions related to them.

A further aim of the study was to anticipate future work patterns in order to assist in workforce planning. After disregarding defaced and largely incomplete papers, there was a useable response rate of 94\% (436). Statistical analysis was carried out with SPSS version 10, using cross-tabulations to compare responses from different groups.

\section{RESULTS}

Respondents were asked to describe their ethnic origin and were given several options or alternatively they could specify their origin themselves. Hence some respondents considered themselves to be from a specific country eg Pakistan, and other stated they were Asian. Groups with small numbers were considered together as 'Others'.

\section{Working hours}

The group was asked to state whether they intended to work full or part time when they started practising as a dentist. A total of $92.2 \%$ of the male respondents stated that they would work full time, as would $90.4 \%$ of the females. A very small proportion of both males $(1.8 \%)$ and females $(2.3 \%)$ planned to work part time at this stage.

\section{Earnings}

On average, the cohort thought they would be earning £28,378 five years into their career. Given current salary levels and inflation, it may be expected that an average salary in 2008 would be around $£ 40,000$ in a hospital training post, and £50,000 in general dental practice. Figure 1 shows the differences in anticipated salary between the sexes, with the male respondents expecting to earn an average of $£ 30,723$ compared with $£ 25,991$ for females. Despite this, both sexes had the same median and mode values $(£ 30,000)$. In addition, individual ethnic groups showed wide variation in mean expected salaries, with individuals of Pakistani origin and those who considered themselves to be Asian anticipating earning most, with £38,228 and £36,317 respectively. The respondents identifying themselves as white stated they thought they would earn a mean salary of $£ 27,701$ with those of Indian origin expected the lowest salary of $£ 21,000$. None of these differences were significant, however, due to small numbers in some categories, and when the values were grouped into bands the differences were much less obvious.

\section{Career plans}

91.7\% of the participants in the study, were aware of the different career pathways available upon graduation, whilst $0.7 \%$ admitted they were not. $64.9 \%$ stated that they wished to enter general dental practice, with $15.1 \%$ intending to go into the hospital dental service, $4.1 \%$ the community dental services and $2.8 \%$ planned to enter the armed forces. A further 12.2\% were undecided. The different career plans noted between the sexes are shown in Table 1, although this variation was not found to be significant (Chi-squared $=6.883, \mathrm{p}=0.076$ ).

Significant variation was seen, however, when responses were compared between ethnic groups, as in Table 2. A greater proportion of white origin students expressed a preference to enter general dental practice. Although the majority of the other ethnic groups also intended to enter general dental practice, the hospital and community dental services were sig-

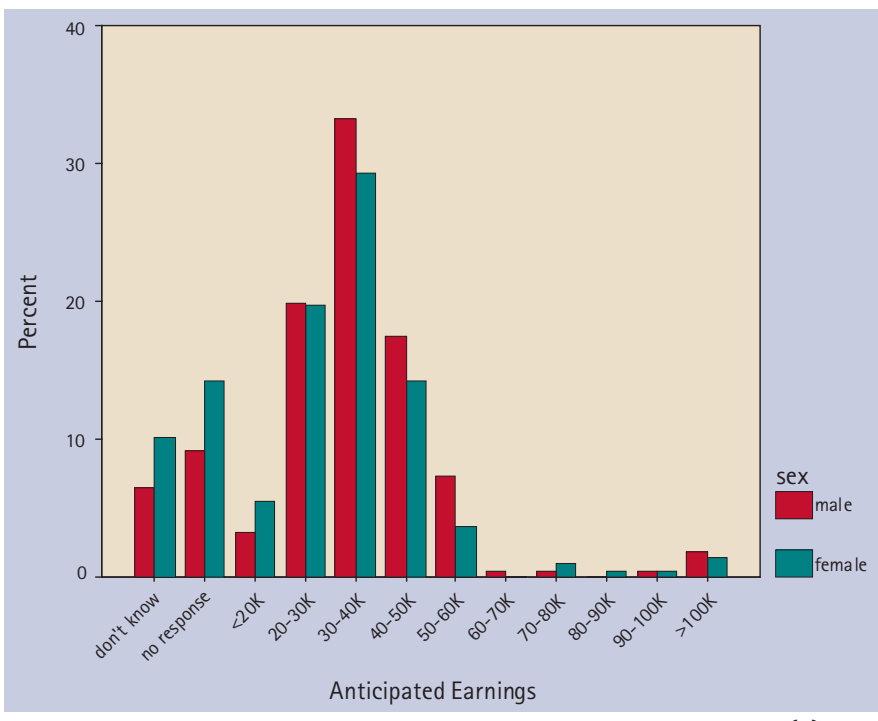

Fig 1 Anticipated earnings of respondents five years into their careers ( $\mathrm{E}$ )

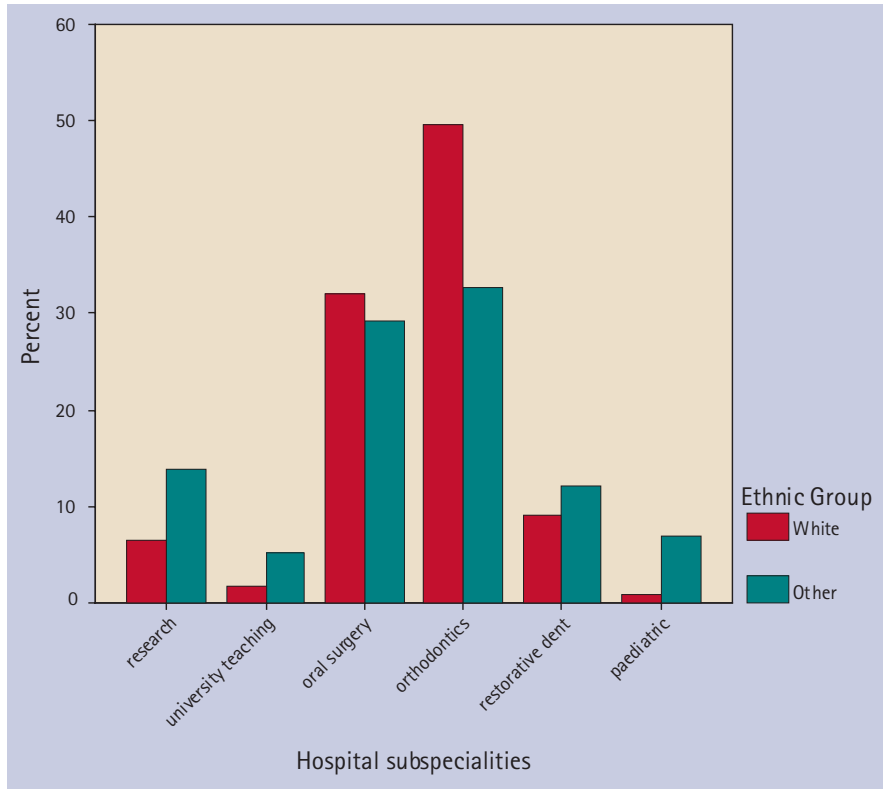

Fig 2 Subspecialty respondents would enter hospital dental service.

Table 1 Percentage of respondents wishing to enter differing fields within dentistry $v$ gender (number).

\begin{tabular}{lcc}
\hline & Male & Gender \\
\hline General dental practice & $80.3(155)$ & Female \\
\hline Hospital dental service & $13(25)$ & $68.8(128)$ \\
\hline Community dental service & $4.1(8)$ & $22(41)$ \\
\hline Armed forces & $2.6(5)$ & $5.4(10)$ \\
\hline
\end{tabular}

nificantly more popular choices (Chi-squared $=14.635, \mathrm{p}<$ 0.05).

The respondents who selected the hospital dental service $(15.1 \%)$ were asked which subspecialty they wished to pursue, and orthodontics was the most favoured choice (43.7\%), followed by oral surgery (31.1\%), restorative dentistry $(10.2 \%)$ and research (9\%). Figure 2 shows the significant variation that was again seen when white origin students were compared with ethnic minority students. Half (49.5\%) of the white students wanted to pursue a career in orthodontics, compared to one third $(32.8 \%)$ of non-white students, whilst twice the proportion of non-whites $(13.8 \%)$ stated they would select a career in research (whites 6.4\%) (Chi-squared $=10.624, \mathrm{p}<0.05)$. 


\begin{tabular}{|c|c|c|}
\hline & \multicolumn{2}{|c|}{ Ethnic group } \\
\hline & White & Other \\
\hline General dental practice & $79(214)$ & $63.9(69)$ \\
\hline Hospital dental service & $14.4(39)$ & $25(27)$ \\
\hline Community dental service & $3(8)$ & $9.3(10)$ \\
\hline Armed forces & $3.7(10)$ & $1.9(2)$ \\
\hline
\end{tabular}

\begin{tabular}{ll}
$\begin{array}{ll}\text { Table } 3 \text { Attributes of a professional dentist as rated by respondents } \\
\text { of importance } \\
\text { ong in order }\end{array}$ & Attributes \\
\hline 1 & Has a friendly manner and good relations with patients \\
\hline 2 & Is technically competent \\
\hline 3 & Feels strongly about the oral health of his / her community \\
\hline 4 & Ensures patients participate in treatment decisions \\
\hline 5 & Keeps up to date with new developments in dentistry \\
\hline 7 & Is able to manage staff effectively \\
\hline
\end{tabular}

\begin{tabular}{lcc}
\multicolumn{3}{l}{ Table 4 Appropriate age to start a family v gender of respondents } \\
\hline Age (years) & Male & Gender \\
\hline $25-29$ & $66.8 \%(139)$ & $60.7 \%(130)$ \\
\hline $30-34$ & $25 \%(52)$ & $34.6 \%(74)$ \\
\hline $35-39$ & $4.8 \%(10)$ & $1.4 \%(3)$
\end{tabular}

\begin{tabular}{|c|c|c|}
\hline \multirow[t]{2}{*}{ Age (years) } & \multicolumn{2}{|c|}{ Ethnicity } \\
\hline & White & Other \\
\hline $25-29$ & $62 \%(190)$ & $80.3 \%(94)$ \\
\hline $30-34$ & $34.3 \%(105)$ & $17.9 \%(21)$ \\
\hline $35-39$ & $3.6 \%(11)$ & $1.7 \%(2)$ \\
\hline
\end{tabular}

\begin{tabular}{|c|c|c|c|c|}
\hline & \multicolumn{2}{|c|}{ white } & \multicolumn{2}{|c|}{ other } \\
\hline & Male & Female & Male & Female \\
\hline Not at all & $12.6(19)$ & $1.9(3)$ & $7.8(5)$ & $0(0)$ \\
\hline $\begin{array}{l}\text { Only for the minimum } \\
\text { possible time }\end{array}$ & 41.1 (62) & $32.7(52)$ & 25 (16) & $37.5(21)$ \\
\hline $\begin{array}{l}\text { When children are } \\
\text { pre-school }\end{array}$ & $32.5(49)$ & $57.9(92)$ & $37.5(24)$ & $50(28)$ \\
\hline $\begin{array}{l}\text { Until children are at s } \\
\text { econdary school }\end{array}$ & 5.3 (8) & 5 (8) & 14.1 (9) & $10.7(6)$ \\
\hline $\begin{array}{l}\text { Until children are fully } \\
\text { independent }\end{array}$ & $4(6)$ & $0(0)$ & $14.1(9)$ & $1.8(1)$ \\
\hline $\begin{array}{l}\text { I would give up } \\
\text { work entirely }\end{array}$ & $0.7(1)$ & $0(0)$ & 0 (0) & $0(0)$ \\
\hline Other & $4(6)$ & $2.5(4)$ & $1.6(1)$ & $0(0)$ \\
\hline
\end{tabular}

\section{General dental practice}

Those who stated a desire to work in general dental practice were asked a series of further questions. They were asked about their anticipated career routes following completion of vocational training, and $86.9 \%$ planned to start as an associate then look to buy a partnership after a few years. The remainder was equally split between remaining as an associate and looking for a partnership straight away.

A total of $91.7 \%$ would like to join a group practice, and 89.7\% expressed a wish to work in a mixed NHS/private practice, with $2.8 \%$ wanting to work exclusively in the NHS and $7.5 \%$ in private practice. No significant variations in responses to this section were found between sexes or ethnic groups.

\section{Postgraduate qualifications}

When asked if the cohort felt that gaining a post graduate qualification would advance their career prospects, $72.9 \%$ felt it would, 3.7\% felt it would not and 23.4\% were undecided. Of those who responded, 95\% thought it would improve their professional potential. A significant variation was seen when responses were compared by gender, with $98.8 \%$ females feeling an additional qualification would help, compared with $91.4 \%$ males (Chi-squared $=10.155, \mathrm{p}=0.001$ ).

\section{Attributes of a professional dentist}

The respondents were asked to rank a number of attributes of a professional dentist in their order of importance, see Table 3. Overall 'has a friendly manner and good relationship with patients' was felt to be the most important, followed by 'is technically competent'. The respondents felt having good business sense was least important, followed by being able to manage staff effectively. There was no significant variation between responses from different groups.

\section{Family life}

The cohort felt it appropriate to start a family within the age range 20-37 years, with a mode of 30 years and mean 27.85 years. Grouping the responses into 5-year bands for the ages cited, showed significant differences between both respondent gender and ethnic group, see Tables 4 and 5. The mode band for respondents of both sexes was 25-29 years old, stated by 67\% males and $61 \%$ females. A larger proportion of females tended to favour the 30-34 years band, chosen by 35\% females compared with 25\% males, however the situation was reversed in the 35-39 band, quoted by 5\% males and 1\% females (Chi-squared $=7.930$, $\mathrm{p}<0.05)$. Non-white students favoured starting a family younger, with 80.3\% stating between 25 and 29 years, compared with $62 \%$ of white students (Chi-squared $=14.073, \mathrm{p}<0.05$ ).

\section{Childcare responsibility}

A total of 91.3\% felt that childcare ought to be shared equally between the parents if both worked, while $4.8 \%$ thought it should mainly be the responsibility of the mother. A further 3.2\% gave another option that included grandparents, nanny etc. Although not significant, there was a trend for males to suggest responsibility should be mainly the mother (Chi-squared $=4.061$, $\mathrm{p}>0.05$ ).

\section{Career breaks}

A total of $44.5 \%$ said they would take time out when children were of pre-school age to concentrate on childcare, with $7.1 \%$ planning to take time out until children were at secondary school, and 3.7\% until children were fully independent. A further $6.2 \%$ said they would take no time out at all, while $0.2 \%$ said they would give up work completely. Overall almost $90 \%$ of females and 70\% males would anticipate taking varying lengths of time out before children started school. Comparison by ethnic group showed that more than twice the proportion of the nonwhite group than the white students, would take time out until children had completed primary education, see Table 6 (chisquared=16.600, $\mathrm{p}<0.05$ ).

Half of the respondents (49.4\%) felt that a child would affect their career to a moderate extent, whilst 19\% indicated that they thought their career would be affected to a greater degree, and $25.9 \%$ said it would have less of an effect. No significant variation was seen when comparing responses by gender or ethnic origin. 
Effect of mother working full-time on pre-school child

More than half (53.9\%) felt that a child would suffer if his/her mother worked full-time with $28.9 \%$ of respondents remaining neutral and $16.6 \%$ feeling there would be no effect. No significant difference in attitudes was seen when comparing responses by gender although slightly more females felt a child was not likely to suffer.

Comparison of the responses by ethnic group showed $60.8 \%$ of the non-white students agreed to some extent that a child would suffer, along with $51.7 \%$ of the white students. In addition, twice the proportion of non-white students strongly agreed that the child would suffer (19.2\%, compared to $8.6 \%$ of white students) (Chi-squared=13.498, $\mathrm{p}<0.05$ ).

\section{Effect of mother working part-time on pre-school child}

A larger proportion of respondents gave a neutral response to the statement that a child would be affected by his/her mother working part-time (49.8\%) while $13.1 \%$ agreed they would suffer, and $36.3 \%$ thought they would not.

A greater proportion of females (44.9\%) disagreed that a child would suffer than males (28.4\%), with twice as many females (15.3\%) than males (7\%) strongly disagreeing. Of male respondents, $16.8 \%$ felt a child would be affected by their mother working parttime compared to $9.7 \%$ of females (Chi-squared=19.270, $\mathrm{p}<0.05$ ).

Trends displayed by the different ethnic groups were similar to the scenario where the mother worked full-time, although not quite so marked. Of the non-white student group, 5.8\% strongly agreed that the child would suffer, compared to $1.6 \%$ of the white students. At the other end of the scale, $16.7 \%$ of the non-whites strongly disagreed, compared to $22.8 \%$ of the white group. These findings, however, were not found to be significant (Chi-squared $=15.947$ ).

\section{Effect of time out on a career}

A total of $26.1 \%$ of the respondents felt that taking time out of dental practice to care for children would have a negative effect on their career. A further 30.9\% felt it would not and $40.8 \%$ gave a neutral response.

When gender comparison was considered, 42.4\% females felt time out would not have a negative effect, compared with $20.5 \%$ male students. However $20.8 \%$ of female students felt it would have an effect, along with $32.7 \%$ of male student respondents (Chi-squared=28.226, $\mathrm{p}<0.001$ ).

\section{DISCUSSION}

The authors are aware that the respondents to this study have not yet embarked upon a career in dentistry, so their views may be a little naïve. However they are better informed than the general public, and it is of value to know the general views and expectations of those entering dentistry.

\section{Working time}

Research to date has shown that it is only after the birth of children that male and female work patterns differ ${ }^{2,4,9,11,12}$ so it is therefore not surprising to find that more than $90 \%$ plan to work full time when they start practising dentistry. Their views, however, may change as they get older, qualify and have children. It is also likely that the respondents will be aware that they would be required to spend one year full time carrying out vocational training following qualification.

The fact that $2 \%$ of both males and females indicated that they would plan to work part time is not entirely unexpected since previous research has found that in addition to females, up to $15 \%$ of males work part time in dentistry. ${ }^{3}$

\section{Earnings}

The average income anticipated by the cohort five years into their career was $£ 28,378$. This is comparable with the income they would have, disregarding inflation, in the hospital dental service, but lower than salaries in the community and general dental practice. When inflation over the five-year period is taken into account, the respondents' estimates were $£ 10,000$ to $£ 20,000$ below expected income.

An interesting finding was that females anticipated earning $15 \%$ less than their male counterparts. From this it is possible to speculate that females are less ambitious or less confident, but this contradicts responses to other questions where there was no difference found between the sexes when asked about their confidence to achieve their professional goals and levels of ambition.

\section{Career plans}

The anticipated career plans in this study were similar to those previously found in Scottish dental graduates. ${ }^{9}$ Little difference was apparent between the genders in this study, but more significant variation was seen when examining the career plans of the ethnic groups. General dental practice was more attractive to respondents of white origin, whereas, most other ethnic group respondents intended to enter general dental practice, three times as many selected the community dental services and $10 \%$ more chose hospital dentistry. It is only possible to speculate on the reasons for this difference, but given the significance to the profession, where the proportion of non-white ethnic groups is increasing, it would be important to establish the students' motives.

Further examination of the responses of those who intend to enter general dental practice showed $87 \%$ of both males and females intended to buy a partnership after a few years working as an associate. This proportion compares with $46 \%$ of all women in a previous study who were equity holding principals. ${ }^{13}$ The same study showed $60 \%$ of women working exclusively within the NHS, whereas only $0.9 \%$ of the women respondents in the current survey anticipated working in this way. This may reflect the fact that the applicants have detected problems within NHS dentistry through the media or, and probably more likely, through contact with general dental practitioners during work shadowing. It has been shown that most applicants to dental school do work shadowing before entering a course. ${ }^{14}$

The number of applicants stating that a postgraduate qualification would be beneficial to their career is huge, and may show that the respondents are aware of the commitment to postgraduate education and the requirements for continued professional development in dentistry. In 2000, 48\% of Scottish dentists said they would consider doing an additional qualification, compared with $16 \%$ who currently had one. ${ }^{8}$ A rise in demand for postgraduate study will obviously have profound effects on the system at present, so an option may be to develop the opportunities and improve the support for postgraduate study in GDP or the CDS.

\section{Family life}

Age to start a family

Although most male and female respondents stated their intention to start a family between the ages of 25 and 29, a higher proportion of women would wait until they were 30 to 34 years, presumably to allow themselves time to establish their careers.

\section{Career breaks}

A very small number of females (1.4\%) stated they intended to take no time out of their career when they had children, a sentiment also reflected by $11 \%$ of the males. One third of both males and females would take the minimum time off. More than half of the women (56\%) would take pre-school time off and $7 \%$ would take longer. This compared with one third of males who 
would take pre-school time with $15 \%$ planning to take longer. Another study in the UK in $2001^{6}$ found $27 \%$ of male dental practitioners took a career break, but the majority were due to working in a different profession. The response in the current study was rather surprising given that the career break would be for child rearing reasons, and may have been influenced by respondents' naivety. Nonetheless it does tie in with more than $90 \%$ of both males and females stating that childcare ought to be equally shared between both parents. In addition, two previous studies on women dentists, 10 years apart, showed a trend for shorter career breaks for women and this seems to be continuing. ${ }^{13}$

The fact that twice the proportion of non-white ethnic groups would take the time out until children had finished primary education probably reflects cultural differences regarding family life.

Due to the variation in time people choose to be away from the profession, it is essential, however, that a method of keeping in touch with dentistry is available for those males and females who choose to take time out of their career.

\section{Effect on child of working mother}

Recognising that over half the respondents felt that if a mother worked full time it would have an effect on a child, it would be valuable to investigate whether students would return to work full or part time after a career break. Since a much smaller proportion felt a mother working part time would have a negative influence on a child, it is possible to surmise that many would return to work part time.

\section{CONCLUSIONS}

- If both males and females are going to take career breaks in the future, this will exacerbate the problems of shortages in the dental workforce.

- Although women may be taking shorter breaks when they have children, it would appear that many would still return on a part time basis, again affecting the available workforce.
- Even at this early stage, most applicants recognise that it is unlikely that they will work exclusively in the NHS. Acknowledging the problems that exist at present regarding accessibility to NHS dental care throughout the UK, this response is of great concern.

- Given the large proportion of respondents who felt that a postgraduate qualification would help their career, the implications of this would have a profound effect on the present capacity for postgraduate education. Alternatives to the traditional study route within the hospital setting need to be developed to create pathways for GDPs and dentists in the CDS to work towards further qualifications.

1. Scottish Council for Postgraduate Medical and Dental Education. Workforce planning for dentistry in Scotland. Edinburgh. Scottish Executive 2002.

2. Friend $L A$. The career commitment of female dental graduates. Br DentJ 1973; 135: 22-24.

3. Matthews R W, Scully C. Working patterns of male and female dentists in the UK BrDent J 1994; 176: 463466.

4. Brennan DS, Spencer A J, Szuster F S P. Differences in time devoted to practice by male and female dentists. Br Dent J 1992; 172:348-349.

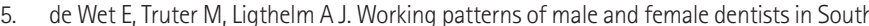
Africa. J Dent Assoc South Africa 1997; 52: 15-17.

6. Newton JT, Buck D, Gibbons D E. Workforce planning in dentistry: The impact of shorter and more varied career patterns. Comm Dent Health 2001; 18: 236-241.

7. Department of Health. Better opportunities for women dentists. London: DH 2002 www.doh.gov.uk/dental/betteropportunitiesforwomendentists

8. Russell E, Harrold T, Watson S. A Scottish survey of general and community dental practitioners 2000. The Toothousand Project. Scottish Council for Postgraduate Medical and Dental Education. March 2001.

9. Baldwin P J, Dodd M, Rennie J S. Careers and patterns of work of Scottish dental graduates: 1991 and 1994. BrDent J 1998; 185: 238-243.

10. Blinkhorn FA, Blinkhorn AS, Tickle M. A profile of the dentists working in the community dental service in the United Kingdom in 1999. Br Dent J 2001; 190: 266268.

11. Newton T, Thorogood N, Gibbons D E. The work patterns of male and female dental practitioners in the United Kingdom. Int Dent J2000; 50: 61-68.

12. Price SS. The profile of women dentists. J Am Dent Assoc 1990; 120: 403-408

13. Seward M H, McEwen M E. The provision of dental care by women dentists in England and Wales in 1985: A ten year review. Br Dent J 1987; 162: 5051.

14. Drummond J R, Duguid R. Work shadowing and career advice sources in dental school applicants. J Dent Res 1996; 76: 1107. 